\title{
Diagnostic and Therapeutic Implications of Cholelithiasis in Children
}

\author{
Nexhmi Hyseni*, Sadik Llullaku, Sejdi Statovci, Murat Berisha, Hysni Jashari, \\ Gani Ceku, Sali Grajqevci, Fjolla Hyseni \\ University Clinical Centre of Kosova, Pediatric Surgery Clinic, Prishtina, Kosovo \\ Email: "nexhmi_h@yahoo.com
}

Received 29 January 2016; accepted 15 March 2016; published 18 March 2016

Copyright (C) 2016 by authors and Scientific Research Publishing Inc.

This work is licensed under the Creative Commons Attribution International License (CC BY). http://creativecommons.org/licenses/by/4.0/

(c) (i) Open Access

\begin{abstract}
Introduction: Cholecystitis, for a long time considered as a disease of adults, has had an increased documented incidence of non-haemolitic cholelithiasis in the Pediatric Surgery practice in the last 20 years. Even though diseases of the gall bladder are rare in children, pediatric patients account for $4 \%$ of all cases with cholecystectomy. Cholecystitis and other diseases of the gall bladder should be considered in differential diagnosis in every patient with abdominal pain in the right upper quadrant, followed by jaundice, especially in children with history of hemolysis. Aim: The aim is to discuss the diagnostic and therapeutic modalities in 6 children with acute cholecystitis and cholelithiasis diagnosed and treated at the clinic of the authors. Patients and Methods: In the last 5 years, at UCCK, 6 patients under 12 years of age were operated, cholecystectomy was performed. The disease was more prevalent in female patients $(66.66 \%-4$ patients) than in male patients $(33.33 \%-$ 2 patients). Mean age was 8.6. Clinical manifestations presented: increased body temperature, abdominal pain and abdominal tenderness during examination. Other clinical manifestations included: vomiting in 4 patients $(66.66 \%)$, jaundice in 2 patients $(33.33 \%)$. Lab results showed leucosytosis in 3 patients $(50 \%)$, disorders of the liver in 2 patients $(33 \%) .2$ patients were diagnosed with spherocytosis and splenomegaly, 1 patient had empyema of gall bladder (wall thickness of the gall bladder $>3.7 \mathrm{~mm}$ ). Clinical diagnosis was confirmed with ultrasound. Ultrasound criteria are: gall bladder thickness $(3.5 \mathrm{~mm})$, stones ose sludge with acoustic shadow, and collection of liquid around gall bladder (pericholecystitis). Results: All patients were initially treated with naso-gastric tube (suction), fluids and antibiotics. Cholecystectomy was performed in 4 patients and cholecystectomy with splenectomy in 2 patients due to spherocytosis. Discussion and conclusion: Cholelithiasis in children is most commonly associated with haemolitic and haemoglobin diseases (Hereditary Spherocytosis, Sideropenic Anaemia, Thalasemia etc.). The incidence of cholesterol stones is higher than pigment stones. Cholecystitis and cholelithiasis in children are more common than previously thought. Ultrasound confirms with great accuracy the presence of stones and acalculous cholesytitis. Treatment is usually surgical, laparoscopic or open surgery, depending on the stage of the disease and the experience of the surgeon.
\end{abstract}

${ }^{*}$ Corresponding author.

How to cite this paper: Hyseni, N., Llullaku, S., Statovci, S., Berisha, M., Jashari, H., Ceku, G., Grajqevci, S. and Hyseni, F. (2016) Diagnostic and Therapeutic Implications of Cholelithiasis in Children. Surgical Science, 7, 144-149.

http://dx.doi.org/10.4236/ss.2016.73019 


\section{Keywords}

\section{Pediatric Cholelithiasis}

\section{Introduction}

Even though diseases of the gall bladder are rare in children, pediatric patients make up to $4 \%$ of all cases with cholecystectomy. Cholelithiasis which presnets as a consequence of extrahepatic or intrahepatic diseases is a well known entity and a widely studied health problem in children [1]-[3].

Cholecystitis, for a long time considered as a disease of the adults, however in the last 20 years, has been documented in pediatric practice with an increased incidence of non-haemolitic cholelithiasis.

Congenital haemolitic anaemia, spherocytosis, and thalassemia are the most common haematologic diseases associated with cholelithiasis [4] [5]. Recently, cases with idiopathic cholelithiasis have increased in relations with these diseases in 50\% of patients [6] [7]. The most common clinical manifestations are: food intolerance, nausea, vomiting and abdominal pain. Treatment is conservative and surgical.

\section{AIM}

In this study, 6 patients with acute cholecystitis and cholelithiasis diagnosed and treated at tha authors clinic.

\section{Material and Methods}

The series of our cases includes 6 children under age of 12, treated by cholecystectomy due to gall bladder stones. Conservative treatment has been administered in all these cases for more than 12 months.

Ultrasound has been performed in all cases to confirm diagnosis and differentiate possible duodenal, pancreatic, and renal problems, especially to exclude anomalies of the choledocus-pancreatic junction. Liver function tests and haemoglobin tests were also performed to exclude metabolic disorders. Surgical approach was with open classic cholecystectomy and in two cases splenectomy was performed due to spherocytosis. Elements of the Calot anatomical region were identified, art. cystica and ductus cysticus were ligated and cut by scissors.

Intraoperative cholangiography was not performed in any of the cases. All patients manifested perystalsis on the second postop day and light nutrition regime was initiated (tea, milk 1.2) All patients were followed up clinically and with ultrasound 1, 6, 12 and 24 months after surgery. Liver function tests and haemoglobin have been asked for in two cases with splenectomy.

\section{Results}

The disease was more prevalent in female patients 4 (66.66\%) than in male patients 2 (33.33\%). Mean age was 8.6. Clinical manifestations presented: increased body temperature, abdominal pain and abdominal tenderness during examination. Other clinical manifestations included: vomiting in 4 patients (66.66\%), jaundice in 2 patients (33.33\%). Lab results showed leucocytosis in 3 patients (50\%), disorders of the liver in 2 patients (33\%). 2 patients were diagnosed with spherocytosis and splenomegaly, 1 patient had empyema of gall bladder (wall thickness of the gall bladder $>3.7 \mathrm{~mm}$ ). All patients were initially treated with naso-gastric tube (suction), fluids and antibiotics.

Table 1 presents distribution of the cases according to gender, age, associated diseases and operative procedures. Cholecystectomy was performed in 4 patients and cholecystectomy with splenectomy in 2 patients due to spherocytosis.

In one patient, the gallbladder was duplex, with a bifid cysticus (Pictures 1-5).

Mean operating time was 56 min and 150 minutes in patient with cholecystectomy and splenectomy performed. There were no operative complications or redo procedures, postop pain was treated with Diclophenac suppositories. In patients with spherocytosis/splenectomy Pneumovax vaccine was administered preop according to the protocol for elective splenectomy. Patients were followed up postop afte 1, 6, 12 and 24 months. Clinical and cosmetic outcome was satisfactory. 


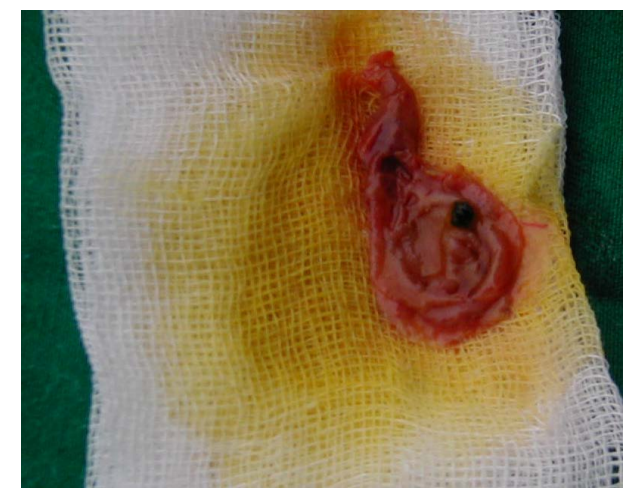

Picture 1. Intraoperative macroscopic aspect of gallbladder stones.

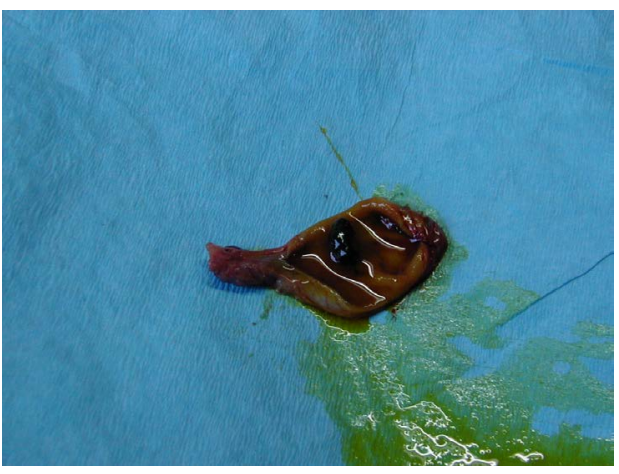

Picture 2. Intraoperative appearance of the pigmented stones.

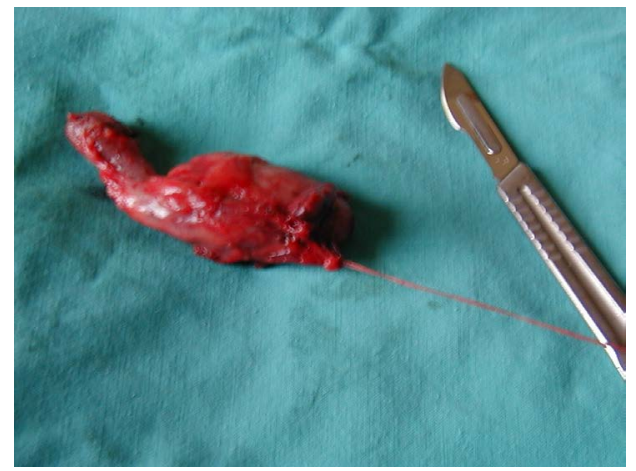

Picture 3. Bifid gallbladder.

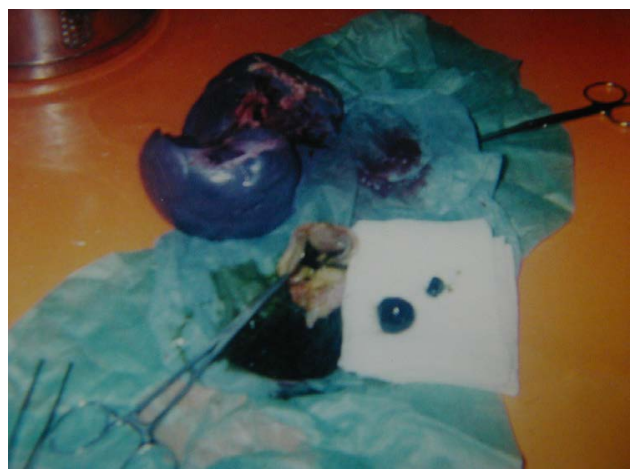

Picture 4. Splenectomy due to spherocytosis and gallbladder pigmented stones. 


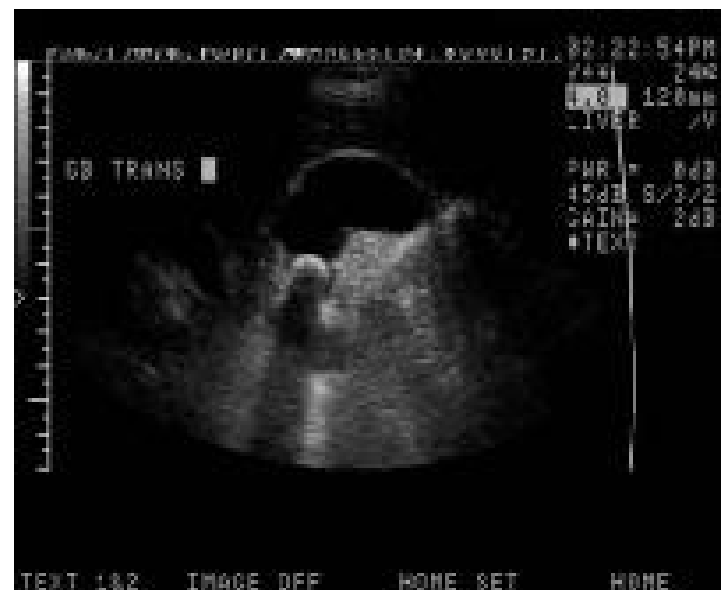

Picture 5. Ultrasound images of cholelithiasis in children.

Table 1. Distribution of the cases according to the age, gender, associated disease, and operative procedure.

\begin{tabular}{|c|c|c|c|c|}
\hline Patient & Age/gender & Clinical diagnosis & Associated diseases & Operative procedures \\
\hline E. Sh & 11year/M & Cholecystitis calculosa & Spherocytosis & Cholecystectomy and Splenectomy ${ }^{*}$ \\
\hline B.R & $7 \mathrm{yr} / \mathrm{F}$ & $\begin{array}{c}\text { Cholelithiasis, empyema } \\
\text { of the gallbladder }\end{array}$ & Acute pancreatitis and jaundice & Conservative treatment-Cholecystectomy ${ }^{*}$ \\
\hline F. E & $7 \mathrm{yr} / \mathrm{M}$ & Cholecystitis calculosa & Spherocytosis & Cholecystectomy and Splenectomy ${ }^{*}$ \\
\hline K. U & $11 \mathrm{yr} / \mathrm{F}$ & Cholecystitis calculosa & Cholecysta duplex cong. & Cholecystectomy $^{*}$ \\
\hline A B & $10 \mathrm{yr} / \mathrm{F}$ & Cholecystitis calculosa & - & ${ }^{\mathrm{Ls}}$ Laparoscopic Cholecystectomy \\
\hline A. B & $6 \mathrm{yr} / \mathrm{F}$ & Cholecystitis calculosa & - & ${ }^{\mathrm{Ls}}$ Laparoscopic Cholecystectomy \\
\hline
\end{tabular}

* Open surgery/Laparotomy-cholecystectomy and Spelenectomy; ${ }^{\mathrm{Ls}}$ Laparoscopic Cholecystectomy.

\section{Discussion}

Cholelithiasis in children is not common and most of the patients are asymptomatic [3] [8]-[10]. The usual cause of gallstones in children was hemolitic disease. Hereditary spherocytosis ,sicke cell anemia , and thalassemia are the most common hemolytic disorders resulting in the development of gallstones (aschcraft) [11]-[16]. Cholesteroll gallstones appear to occur in children and adolescents because of the same pathophysiologic disturbances that cause these stones in adult Ashcraft.

The incidence of cholesterol stones is higher than pigment stones [5] [7] [17]-[21]. Cholecystitis and cholelithiasis in children are more common than previously thought [13] [19] [22]. Children with increased risk for the disease are prematures that have been administered with furosemid and those that were administered parenteral therapy [1]. Predisposing factors for gallbladder stones are: children with total parenteral nutrition, ileum resection, sepsis and haemolitic diseases [1] [9] [23] [24]. In infants, cholelithiasis can spontaneously regress (fetal cholelithiasis) but they can too manifest themselves with clinical symptoms and complications due to predisposing factors [6] [20].

Usual clinical manifestations of cholecystitis and cholelithiasis are not always present in children. Most of them present with non-specific abdominal pain. Some patients (5\% - 10\%) can present with complications like acute pancreatitis and cholecystitis [13] [19]. Eventhough obstructive jaundice due to the presence of stones in the choledocus is rare, it has been reprted in literature [19]. Liver function tests are normal. X-ray of the abdomen can show calcificates.

Ultrasound confirms with great accuracy the presence of cholelithiasis and acalculous cholecystitis [25].

Treatment is usually surgical [2] [4] [7] [9] [19] [22]. Data for therapeutic treatment are: lithotripsy and bile acid stone dissolution are not discribed in literature of Pediatric Surgery [12]. 


\section{Conclusions}

In our experience, there were no specific contraindications for laparoscopic cholecystectomy but this was not performed due to the lack of equipment. We do not believe that intraoperative cholangiography is necessary because of a very small risk of stone migration in choledocus as well as due to a good anatomical visualization of the anatomic elements in the Calot region.

There is no need for drain if the hemostasis is properly conducted and the dissection of the tissue is careful. We consider that open surgery is a gold standard in our circumstances because the complication rate is not considerably higher than with laparoscopic surgery. Cholecystectomy and splenectomy are indicated in patients with haemolitic diseases and associated cholelithiasis.

\section{References}

[1] Bellows, C.F., Berger, D.H. and Crass, R.A. (2005) Management of Gallstones. American Family Physician, 72, 637642.

[2] Bonnard, A., Seguier-Lipszyc, E., Liguory, C., et al. (2005) Laparoscopic Approach as Primary Treatment of Common Bile Duct Stones in Children. Journal of Pediatric Surgery, 40, 1459-1463. http://dx.doi.org/10.1016/j.jpedsurg.2005.05.046

[3] Stringer, M.D., Soloway, R.D., Taylor, D.R., Riyad, K. and Toogood, G. (2007) Calcium Carbonate Gallstones in Children. Journal of Pediatric Surgery, 42, 1677-1682. http://dx.doi.org/10.1016/j.jpedsurg.2007.05.022

[4] Alonso, M.H. (2004) Gall Bladder Abnormalities in Children with sickle Cell Disease: Management with Laparoscopic Cholecystectomy. The Journal of Pediatrics, 145, 580-581. http://dx.doi.org/10.1016/j.jpeds.2004.08.041

[5] Currò, G., Meo, A., Ippolito, D., Pusiol, A. and Cucinotta, E. (2007) Asymptomatic Cholelithiasis in Children with Sickle Cell Disease: Early or Delayed Cholecystectomy? Annals of Surgery, 245, 126-129. http://dx.doi.org/10.1097/01.sla.0000242716.66878.23

[6] Wesdorp, I., Bosman, D., de Graaff, A., Aronson, D., van der Blij, F. and Taminiau, J. (2000) Clinical Presentations and Predisposing Factors of Cholelithiasis and Sludge in Children. Journal of Pediatric Gastroenterology and Nutrition, 31, 411-417. http://dx.doi.org/10.1097/00005176-200010000-00015

[7] Mehta, S., Lopez, M.E., Chumpitazi, B.P., Mazziotti, M.V., Brandt, M.L. and Fishman, D.S. (2012) Clinical Characteristics and Risk Factors for Symptomatic Pediatric Gallbladder Disease. Pediatrics, 129, e82-e88. http://dx.doi.org/10.1542/peds.2011-0579

[8] Stringer, M.D., Taylor, D.R. and Soloway, R.D. (2003) Gallstone Composition: Are Children Different? The Journal of Pediatrics, 142, 435-440. http://dx.doi.org/10.1067/mpd.2003.159

[9] Koivusalo, A., Pakarinen, M., Gylling, H. and Nissinen, M.J. (2015) Relation of Cholesterol Metabolism to Pediatric Gallstone Disease: A Retrospective Controlled Study. BMC Gastroenterology, 15, 74. http://dx.doi.org/10.1186/s12876-015-0304-4

[10] Svensson, J. and Makin, E. (2012) Gallstone Disease in Children. Seminars in Pediatric Surgery, 21, 255-265. http://dx.doi.org/10.1053/j.sempedsurg.2012.05.008

[11] Vrochides, D.V., Sorrells Jr., D.L., Kurkchubasche, A.G., Wesselhoeft Jr., C.W., Tracy Jr., T.F. and Luks, F.I. (2005) Is There a Role for Routine Preoperative Endoscopic Retrograde Cholangiopancreatography for Suspected Choledocholithiasis in Children? Archives of Surgery, 140, 359-361. http://dx.doi.org/10.1001/archsurg.140.4.359

[12] Siddiqui, S., Newbrough, S., Alterman, D., Anderson, A. and Kennedy Jr., A. (2008) Efficacy of Laparoscopic Cholecystectomy in the Pediatric Population. Journal of Pediatric Surgery, 43, 109-113. http://dx.doi.org/10.1016/j.jpedsurg.2007.09.031

[13] Kinney, C.K. and Erickson, H.C. (1990) Modeling the Client's World: A Way to Holistic Care. Issues in Mental Health Nursing, 11, 93-108. http://dx.doi.org/10.3109/01612849009014547

[14] Tannuri, A.C., Leal, A.J., Velhote, M.C., Gonlçalves, M.E. and Tannuri, U. (2012) Management of Gallstone Disease in Children: A New Protocol Based on the Experience of a Single Center. Journal of Pediatric Surgery, 47, 2033-2038. http://dx.doi.org/10.1016/j.jpedsurg.2012.06.010

[15] Leitzmann, M.F., Giovannucci, E.L., Rimm, E.B., et al. (1998) The Relation of Physical Activity to Risk for Symptomatic Gallstone Disease in Men. Annals of Internal Medicine, 128, 417-425. http://dx.doi.org/10.7326/0003-4819-128-6-199803150-00001

[16] Leitzmann, M.F., Rimm, E.B., Willett, W.C., et al. (1999) Recreational Physical Activity and the Risk of Cholecystectomy in Women. The New England Journal of Medicine, 341, 777-784. 
http://dx.doi.org/10.1056/NEJM199909093411101

[17] Kaechele, V., Wabitsch, M., Thiere, D., et al. (2006) Prevalence of Gallbladder Stone Disease in Obese Children and Adolescents: Influence of the Degree of Obesity, Sex, and Pubertal Development. Journal of Pediatric Gastroenterology and Nutrition, 42, 66-70. http://dx.doi.org/10.1097/01.mpg.0000187816.31213.06

[18] Rocca, R., Castellino, F., Daperno, M., et al. (2005) Therapeutic ERCP in Paediatric Patients. Digestive and Liver Disease, 37, 357-362. http://dx.doi.org/10.1016/j.dld.2004.09.030

[19] Al-Salem, A.H. and Issa, H. (2012) Laparoscopic Cholecystectomy in Children with Sickle Cell Anemia and the Role of ERCP. Surgical Laparoscopy, Endoscopy \& Percutaneous Techniques, 22, 139-142. http://dx.doi.org/10.1097/SLE.0b013e3182471b1c

[20] Della Corte, C., Falchetti, D., Nebbia, G., et al. (2008) Management of Cholelithiasis in Italian Children: A National Multicenter study. World Journal of Gastroenterology, 14, 1383-1388. http://dx.doi.org/10.3748/wjg.14.1383

[21] St Peter, S.D., Keckler, S.J., Nair, A., et al. (2008) Laparoscopic Cholecystectomy in the Pediatric Population. Journal of Laparoendoscopic \& Advanced Surgical Techniques A, 18, 127-130. http://dx.doi.org/10.1089/lap.2007.0150

[22] Dalton, S.J., Balupuri, S. and Guest, J. (2005) Routine Magnetic Resonance Cholangiopancreatography and IntraOperative Cholangiogram in the Evaluation of Common Bile Duct Stones. Annals of the Royal College of Surgeons of England, 87, 469-470. http://dx.doi.org/10.1308/003588405X51137

[23] Bonfrate, L., Wang, D.Q., Garruti, G. and Portincasa, P. (2014) Obesity and the Risk and Prognosis of Gallstone Disease and Pancreatitis. Best Practice \& Research Clinical Gastroenterology, 28, 623-635. http://dx.doi.org/10.1016/j.bpg.2014.07.013

[24] Prince, J.S. and Senac Jr., M.O. (2003) Ceftriaxone-Associated Nephrolithiasis and Biliary Pseudolithiasis in a Child. Pediatric Radiology, 33, 648-651. http://dx.doi.org/10.1007/s00247-003-0963-0

[25] Nakken, K.E., Labori, K.J., Rodningen, O.K, et al. (2009) ABCB4 Sequence Variations in Young Adults with Cholesterol Gallstone Disease. Liver International, 29, 743-747. http://dx.doi.org/10.1111/j.1478-3231.2008.01914.x 